\title{
Strong aftershocks in the northern segment of the Wenchuan earthquake rupture zone and their seismotectonic implications
}

\author{
Yong Zheng ${ }^{1,5}$, Sidao $\mathrm{Ni}^{2}$, Zujun $\mathrm{Xie}^{1}$, Jian $\mathrm{Lv}^{3}$, Hongsheng $\mathrm{Ma}^{4}$, and Paul Sommerville \\ ${ }^{1}$ Institute of Geodesy and Geophysics, Chinese Academy of Sciences, Wuhan, China, 430077 \\ ${ }^{2}$ Mengcheng National Geophysical Observatory and School of Earth and Space Science. \\ University of Science and Technology of China, Hefei, China, 230026 \\ ${ }^{3}$ Earthquake Adminstration of Jiangxi Province, Nanchang, 330039, China \\ ${ }^{4}$ Institute of Earthquake Science, Chinese Earthquake Adminstration, Beijing, China, 100086 \\ ${ }^{5}$ Institute of Geophysics, Chinese Earthquake Adminstration, Beijing, China, 100086 \\ ${ }^{6}$ URS Corp, Pasadena, CA, USA, 91106
}

(Received October 15, 2008; Revised April 3, 2009; Accepted June 10, 2009; Online published January 26, 2011)

\begin{abstract}
More than 28,000 aftershocks have occurred since the 05/12/2008 Wenchuan earthquake, with dozens of them stronger than $M$ 5. Since July, 2008, all the $M>5$ earthquakes have occurred only in the northern segment of the rupture zone, suggesting obvious seismicity segmentation. We applied the double difference method to relocate all of the $M>3$ aftershocks. After relocation, the aftershocks show a compact zone of seismicity, with a length of about $300 \mathrm{~km}$ and average width of $30 \mathrm{~km}$, supporting that the hypothesis that the Beichuan-Yingxiu and Chaping-Linjiaan faults are the faults that ruptured in the earthquake. With the Cut and Paste (CAP) waveform inversion algorithm, we determined the source mechanism and focal depth of all the $>M 5$ aftershocks in the northern segments. The number of thrust events is close to the number of strike-slip events, but almost all of the events with thrust mechanism are distributed over the northern segment, while the aftershocks with strike-slip mechanism only occurred at the north-easternmost end, contrasting with eld observations of a substantial strikeslip component of surface rupture over the northern segment. The events with strike-slip mechanism occurred at depths up to $18 \mathrm{~km}$, consistent with the lack of surface rupture in the north-easternmost section. However, since early August, very shallow events $(2 \mathrm{~km})$ with thrust mechanism have occurred, probably releasing the strain energy of the unruptured fault in the north-easternmost section. It seems that the seismic hazard potential of the northern segment is still quite high, and more studies are needed to resolve some of the discrepancy suggested by aftershock patterns and other observations.
\end{abstract}

Key words: Source mechanism, Cut and Paste method, focal depth, aftershock, seismicity segmentation.

\section{Introduction}

The great Wenchuan earthquake occurred along the border between the Tibetan plateau and the Sichuan basin, manifested by the complicated Longmenshan fault system consisting of multiple faults from many stages of evolution (Burch el et al., 1995, 2008). It is conceivable that rupture processes in such a complicated fault system could involve much more complexity than the simple case of rupture of a single planar fault. Though many waveform studies involving telseismic $P$ and $S H$ waves have yielded a more or less consistent picture of the rupture processes, many issues remain to be resolved before researchers have a complete understanding of the details of this earthquake (Hayes and Ji, 2008; Nishimura and Yagi, 2008; Wang et al., 2008). One puzzling feature of the earthquake is that high angle surface rupture is observed over more than $200 \mathrm{~km}$ of the fault trace (Zhang et al., 2008), but teleseismic models typically assume low angle faults (about 30 degree) with a rupture

Copyright (c) The Society of Geomagnetism and Earth, Planetary and Space Sciences (SGEPSS); The Seismological Society of Japan; The Volcanological Society of Japan; The Geodetic Society of Japan; The Japanese Society for Planetary Sciences; TERRAPUB.

doi:10.5047/eps.2009.06.001 length of up to $300 \mathrm{~km}$ (Hayes and Ji, 2008; Nishimura and Yagi, 2008). Although Wang et al. (2008) assumed faults with variable dip at different depths, their study is based only on forward modeling and does not indicate the sensitivity to dip of the fault. To resolve the fault geometry, the aftershock distribution can provide valuable constraints, and high-accuracy aftershock distribution has been a successful approach in con rming bent faulting planes (Wu and Takeo, 2004). Therefore, it is critical to study the aftershocks in detail to understand the structure of the fault system.

Another important aspect of an aftershock study is that the mechanisms of aftershocks provide important clues to the mechanism of the main shock. As various studies have demonstrated, the Wenchuan mainshock probably started as a thrust event, evolved into at mechanism with almost equal thrust and strike-slip components, and eventually became a strike-slip dominant mechanism for the last $100 \mathrm{~km}$ of the rupture zone (Hayes and Ji, 2008; Nishimura and Yagi, 2008). However, eld investigations of surface rupture show different results (Liu et al., 2008; Zhang et al., 2008). After detailed mapping, Liu et al. (2008) proposed that the rupture zone of the Wenchuan Earthquake can be 


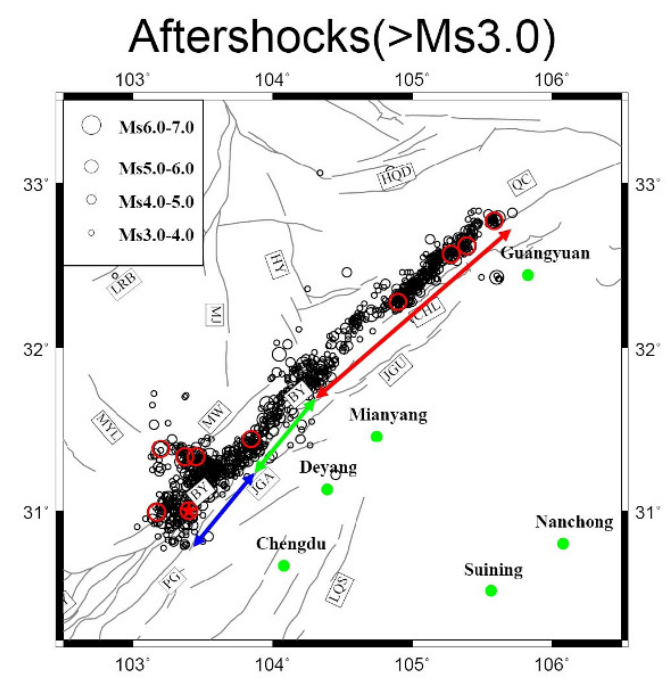

Fig. 1. Distribution of aftershocks (black circles) with $M>3.0$, after relocation with the double-difference method combined with the master event method. Aftershocks stronger than $M_{\mathrm{S}} 5.6$ (red circles) are used as master events. Circle size corresponds to earthquake magnitude. The solid red star shows the epicenter of the main shock. The dark gray lines represent the Quaternary active faults (Zhang et al., 2008). Fault names given by abbreviations in boxes are: XSH: Xianshuihe Fault, YLX: Yulongxi Fault, FBH: Fubianhe Fault, MJ: Minjiang Fault, HY: Fuya Fault, DKL: East Kunlun Fault, HQD: Hanan-Qingshanwan Fault, DB: Diebu-Bailongjiang Fault, LRB: Longriba Fault, AB: Aba Fault, QC: Qingchuan Fault, LY: Lueyang-Mianxian Fault, LL: Lixian-Luojiabao Fault, LJ: Lixian-Jiangkou Fault, XQL: West Qingling north boundary Fault, PG: Pengxian-Guanxian Fault, BY: Beichuan-Yingxiu Fault, JGA: Jiangyou-Guanxian Fault, JGU: Jiangyou-Guangyuan Fault, LQS: Longquanshan Fault, CHL: Chaba-Linansi Fault, MW: Maoxian-Wenchuan Fault, MYL: Miyaluo Fault.

divided into three segments. The southern segment ruptured along the Beichuan-Yingxiu fault and covers a length of about $50 \mathrm{~km}$ from the epicenter. This segment has a large vertical scarp up to $6 \mathrm{~m}$ high, with a thrust component stronger than strike-slip component. The middle segment consists of two ruptured faults, the Beichuan-Yingxiu fault and the JiangYou-Guanxian faults, and covers a length of about $50 \mathrm{~km}$, also with more thrust component. The northern segment consisted of surface rupture on one fault, the Beichuan-Yingxiu fault, and its extension towards the northeast, the Chaba-LinAnsiAn fault (Fig. 1). The surface break of the northern segment shows similar amounts of strike-slip and thrust motion, in contrast to the predominant strike-slip motion in the models by Hayes and $\mathrm{Ji}$ (2008) and Nishimura and Yagi (2008). The southern segment corresponds to the teleseismically resolved area of the epicenter and maximum slips, while the northern segment corresponds to a section of mostly strike-slip mechanism (Nishimura and Yagi, 2008). However, the finite fault model of Wang et al. (2008) did not show a predominant strike slip mechanism. The middle segment may be related to the transition between the southern and northern segment. Since most aftershocks close to the faulting plane show mechanisms similar to that of the main shock, accurate mechanisms of aftershocks should be helpful in understanding the mechanism of the main shock rupture.

The finding that the northern segment produced the strongest aftershocks is also surprising. According to the catalog by the China Earthquake Network (CEN), the strongest aftershock $\left(M_{\mathrm{S}} 6.5\right)$ on May 25, 2008 occurred just on the north-eastern most end. Also, since late July, all the aftershocks stronger than M5.0 occurred in the northern segment. The southern and middle segments are better studied, and field observations of surface breaks are consistent with the teleseismic inversion. Therefore, we focus our attention on the aftershocks in the northern segment in order to address the discrepancy between geological and seismological observations of the rupture process in the northern segment.

We report first on the relocation of aftershocks stronger than $M 3$, then on the depth and mechanisms of major aftershocks ( $>M 5$ ) from CAP inversion.

\section{Data and Analysis}

The Wenchuan aftershock sequence is well recorded by the CEN, complemented with the fairly dense provincial networks of Sichuan, Gansu, and Shaanxi. Immediately after the mainshock, the China Earthquake Administration (CEA) installed a temporary network of portable seismometers to monitor aftershock activity (Fig. A.1) (Zheng et al., 2009). The average spacing between stations is about $100 \mathrm{~km}$, and is even $50 \mathrm{~km}$ in certain regions. With such relatively dense station coverage, events stronger than $M 5$ can be well recorded by more than dozens of stations with very good azimuthal coverage and, therefore, can be well located even with Geiger's algorithm employing 1D velocity models (Geiger, 1910). It has been demonstrated that the absolute location accuracy of the events is as good as $10 \mathrm{~km}$ or even $5 \mathrm{~km}$ in the Longmenshan region with just the Sichuan provincial network (Zhao et al., 1997). With the temporary network, location accuracy as good as $5 \mathrm{~km}$ is obtained. Moreover, there are many water reservoirs for hydro-power plants which are equipped with short period stations. The aperture of these reservoir seismic networks is fairly small $(20 \mathrm{~km})$, and can therefore provide an accuracy of at least $5 \mathrm{~km}$ for earthquakes occurring within the network.

However, for weaker events around $M 3$, fewer stations recorded the earthquakes with clear arrival of $P$ or $S$ waves. In this case, location accuracy is compromised because of limited azimuthal coverage. A better location algorithm is required to improve accuracy.

\subsection{Relocation with the double difference method}

The double difference method is an effective relative location algorithm which can minimize effects due to unknown velocity structure and station corrections, and this algorithm has been applied extensively in determining the precise location of aftershocks (Waldhauser and Ellsworth, 2000; Chi and Hauksson, 2006). We first calculated the absolute locations of aftershocks stronger than M 5.6 (solid red circles in Fig. 1) with Geiger's algorithm, based on all $P$ and $S$ arrivals recorded by national, provincial, and reservoir stations. We then gave larger weights to these strong aftershocks and employed the double difference method to relocate the $>M 3$ aftershocks of the Wenchuan earthquake mostly with $P$ arrivals. Eventually the time residual is reduced to $0.3 \mathrm{~s}$, and the relative location accuracy is about 
$2 \mathrm{~km}$. However, event depth is the most dif cult parameter to be resolved when there are no nearby stations, and the error in relative depth is about $5 \mathrm{~km}$ for the station distribution in this area. This level of accuracy in relative depth is not high enough to provide good constraints on the dip angle of the fault plane. Also the absolute location of the master events is only $5 \mathrm{~km}$, so the absolute location of the aftershocks is accurate up to $5 \mathrm{~km}$.

After relocation, the aftershocks show a very compact distribution (Fig. 1), with an almost linear trend striking from southwest to northwest. The length of the aftershock zone is about $300 \mathrm{~km}$ and the width is about $30 \mathrm{~km}$. There are several interesting features in the aftershock distribution. Firstly, the north-easternmost end is narrow, suggesting a more vertical fault plane, and the south-westernmost end (also the hypocentral region) is broader, suggesting a shallower dip angle on the fault plane. Secondly, there seems to be a southeast to northwest trend about $30 \mathrm{~km}$ away from the hypocenter of the main shock, and the strike is consistent with that of the Miyaluo fault (MYL) (Fig. 1). Thirdly, there is a bend in the strike of the middle segment (green segment in Fig. 1) as compared to the strike of the whole seismicity zone, suggesting a change in the strike of the fault plane. Therefore, rupture of the main shock seems to be segmented with different dip and strike angles for each segment, and these factors should be taken into account when nite fault inversion is performed to unravel the rupture processes.

\subsection{Resolving depth and focal mechanism with the Cut and Paste method}

The depth of larger events ( $\geq M$ 5) can be determined by waveform modeling with the identi cation of depth phases or grid-searching on whole waveforms (Langston, 1987; Zhu and Helmberger, 1996). The Cut and Paste method (CAP) developed by Zhao and Helmberger (1994) and Zhu and Helmberger (1996) ts $P_{\mathrm{nl}}$ and surface wave separately and are particularly useful in resolving focal depth for two reasons. First, the $P_{\mathrm{nl}}$ wave contains depth phases, and second, the relative amplitude of $P_{\mathrm{nl}}$ and surface waves also constrains the depth. CAP also provides a good estimate of focal mechanisms when the velocity structure is not well known because the $P_{\mathrm{nl}}$ and surface waves are allowed to shift to obtain optimal correlation, thus reducing errors due to velocity models. Moreover, the $P_{\mathrm{nl}}$ and surface waves are given different weights, and the dominance of the surface waves in the inversion can be avoided. Also, waveforms from stations at different distances are corrected with a distance attenuation law to balance the waveform $t$ for closein stations and distant stations; otherwise close-in records would dominate the waveform $\mathrm{t}$ (Zhu and Helmberger, 1996).

The CAP method starts by calculating the nine components of the theoretical Green's function $G_{i}(t)$ with the reectivity method for a $1 \mathrm{D}$ velocity model. Synthetic seismograms $s(t)$ can then be obtained by linear combination of these nine components from three basic fault geometries (Zhu and Helmberger, 1996).

$$
s(t)=M_{0} \sum_{i=1}^{3} A_{i}\left(\theta-\phi_{s}, \delta, \lambda\right) G_{i}(t)
$$

where $M_{0}$ and $A_{i}$ are the moment and coef cients for the three basic fault con gurations, respectively.

The objective is to obtain the maximum $t$ between the observed velocity seismogram $u(t)$ and the synthetic one $s(t)$,

$$
u(t)=s(t)
$$

The maximum $\mathrm{t}$ is based on a norm characterizing the difference between observation and synthetics. Typically, the mis $\mathrm{t}$ error is de ned in least square sense:

$$
e=\left\|\left(\frac{r}{r_{0}}\right)^{p}\right\| \cdot\|u-s\|
$$

where $r$ is epicentral distance and $r_{0}$ is a reference distance. Also, $p$ is chosen to correct amplitude decay with distance, which is set to be 1.0 for the $P_{\mathrm{nl}}$ wave and 0.5 for surface waves (Zhu and Helmberger, 1996). The observed three components (vertical, radial, and tangential) are partitioned into ve parts: two sections of the radial and vertical components of $P_{\mathrm{nl}}$, two sections of the radial and vertical components of the Rayleigh wave, and the tangential component of the Love wave. $P_{\mathrm{nl}}$ and Surface waveforms are allowed to shift by different amounts of time and the total waveform mismatch is the sum of the $P_{\mathrm{nl}}$ waveform mismatch and surface waveform mismatch.

Although CAP allows for inaccurate velocity models, more realistic models de nitely improve the accuracy in resolving depth and mechanism. Extensive geological and geophysical studies have been conducted in the Longmenshan area, and layering in the crust is fairly well understood (Song, 1996). The crustal thickness for the eastern margin of the Tibetan plateau is about $50 \mathrm{~km}$, while the crustal thickness is $40 \mathrm{~km}$ for the Sichuan basin. We adopted an average 1D velocity model based on seismic refraction, tomography, and Crust 2.0 (Song, 1996; Zhao et al., 1997). The average crustal thickness is chosen to be $46 \mathrm{~km}$, and detailed parameters are listed in Table 1.

Although there have been about 200 aftershocks stronger than $M 4$, which can be studied with the CAP method, we choose the 18 strongest ones in the middle segment and northern segment as representative events due to the limited time available for analyzing all the events. These 18 events are stronger than $M_{\mathrm{s}} 5.0$ according to the preliminary China Earthquake Network Center (CENC) catalog (Table 2), and ve of them occurred in the middle segment. When performing the CAP inversion, we search the depth from 1.0 to $25 \mathrm{~km}$ at $1-\mathrm{km}$ intervals, and the fault plane strike, dip,

Table 1. Crustal structure of Longmenshan region. $Q_{a}$ and $Q_{b}$ are the $P$-wave and $S$-wave attenuation $Q$ value.

\begin{tabular}{ccccrc}
\hline $\begin{array}{c}\text { Thickness } \\
(\mathrm{km})\end{array}$ & $\begin{array}{c}V_{s} \\
(\mathrm{~km} / \mathrm{s})\end{array}$ & $\begin{array}{c}V_{p} \\
(\mathrm{~km} / \mathrm{s})\end{array}$ & $\begin{array}{c}\text { Density } \\
\left(\mathrm{g} / \mathrm{cm}^{3}\right)\end{array}$ & $Q_{a}$ & $Q_{b}$ \\
\hline 1.0 & 1.2 & 2.5 & 2.1 & 800 & 400 \\
1.0 & 2.1 & 4.0 & 2.4 & 800 & 600 \\
20.0 & 3.5 & 6.1 & 2.75 & 1000 & 600 \\
20.0 & 3.6 & 6.3 & 2.8 & 800 & 500 \\
4.0 & 4.0 & 7.2 & 3.1 & 1000 & 600 \\
- & 4.48 & 8.04 & 3.32 & 972 & 404 \\
\hline
\end{tabular}



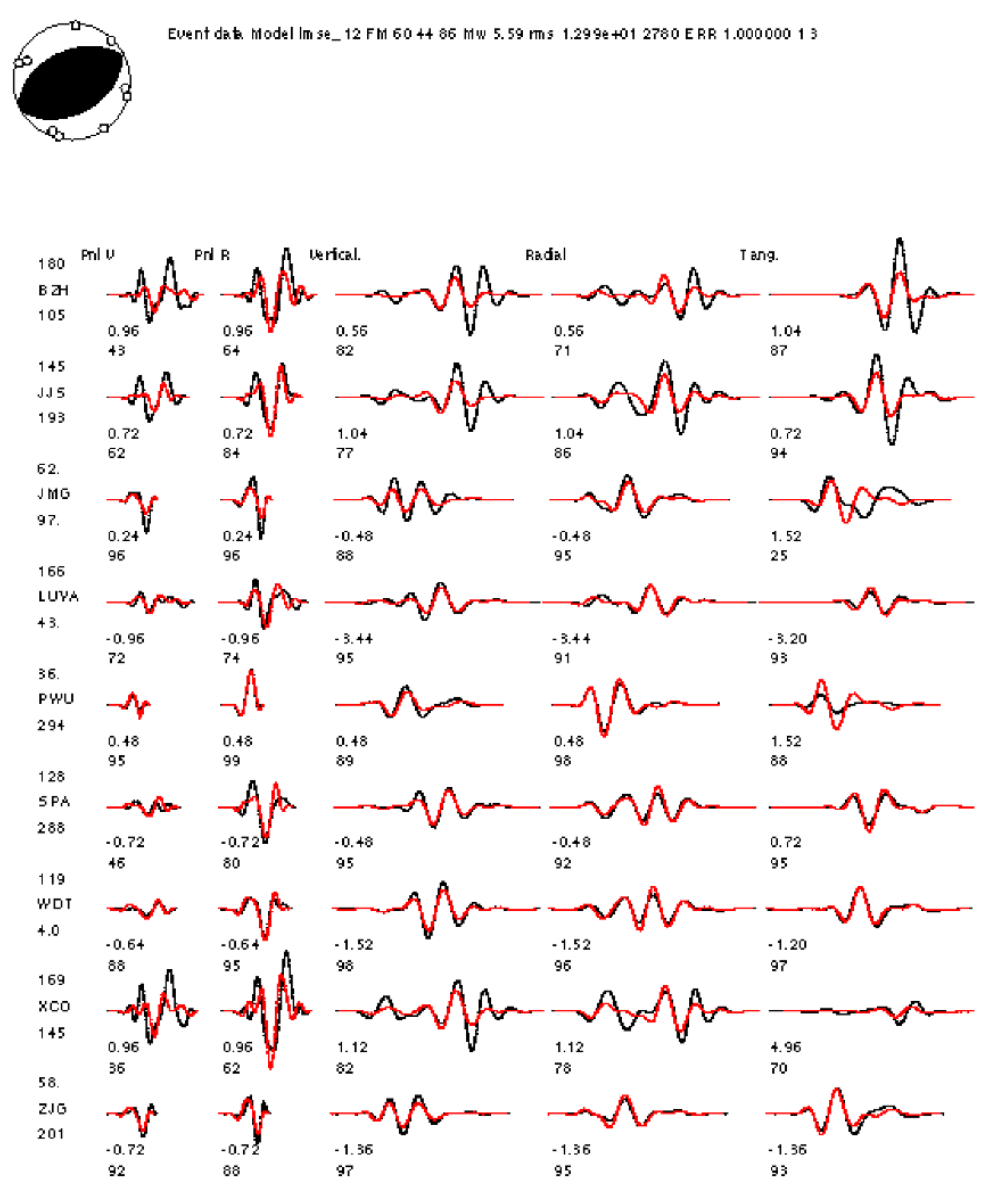

Fig. 2. Comparison between observed and synthetic waveforms for event No. 6 . The red lines are the synthetic waveforms and the black lines are the observed waveforms. The top text line illustrates the fit error and parameters of the earthquake fault plane. The small circles on the beachball indicate a lower hemispherical projection of first-arriving $P$ waves $\left(P_{\mathrm{g}}\right.$ or $\left.P_{\mathrm{n}}\right)$. The first column of numbers above and below the station name are the azimuth and epicentral distance. The first row of numbers beneath each trace are time shifts in seconds required for optimal correlation between synthetic and observed seismic phases (vertical and radial component of $P_{\mathrm{nl}}$, Rayleigh, and tangential component of Love waves from left to right, respectively). Cross correlation is also presented on the second row beneath each trace.

Table 2. Catalog of aftershocks with $M_{\mathrm{s}} \geq 5.0$ (from CEN).

\begin{tabular}{lccccc}
\hline \multicolumn{2}{c}{ Time } & $\begin{array}{c}\text { Latitude } \\
\left({ }^{\circ}\right)\end{array}$ & $\begin{array}{c}\text { Longitude } \\
\left({ }^{\circ}\right)\end{array}$ & $\begin{array}{c}\text { Depth } \\
(\mathrm{km})\end{array}$ & $\begin{array}{c}\text { Magnitude } \\
\left(M_{\mathrm{s}}\right)\end{array}$ \\
\hline $2008 / 8 / 7$ & $16: 15: 33.7$ & 32.1 & 104.7 & 10 & 5.0 \\
$2008 / 8 / 5$ & $17: 49: 18.7$ & 32.8 & 105.5 & 10 & 6.1 \\
$2008 / 8 / 1$ & $16: 32: 44.6$ & 32.1 & 104.7 & 20 & 6.1 \\
$2008 / 7 / 24$ & $15: 09: 28.6$ & 32.8 & 105.5 & 10 & 6.0 \\
$2008 / 7 / 24$ & $03: 54: 46.5$ & 32.8 & 105.6 & 10 & 5.6 \\
$2008 / 7 / 15$ & $17: 26: 21.5$ & 31.6 & 104.0 & 15 & 5.0 \\
$2008 / 6 / 5$ & $12: 41: 08.2$ & 32.3 & 105.0 & 33 & 5.0 \\
$2008 / 5 / 27$ & $16: 37: 53.2$ & 32.8 & 105.6 & 33 & 5.7 \\
$2008 / 5 / 27$ & $16: 03: 24.1$ & 32.7 & 105.6 & 33 & 5.4 \\
$2008 / 5 / 25$ & $16: 21: 46.9$ & 32.6 & 105.4 & 33 & 6.4 \\
$2008 / 5 / 20$ & $01: 52: 36.4$ & 32.3 & 104.9 & 33 & 5.0 \\
$2008 / 5 / 19$ & $14: 06: 54.9$ & 32.5 & 105.3 & 33 & 5.4 \\
$2008 / 5 / 18$ & $01: 08: 23.4$ & 32.1 & 105.0 & 33 & 6.0 \\
$2008 / 5 / 15$ & $05: 01: 08.0$ & 31.6 & 104.2 & 33 & 5.0 \\
$2008 / 5 / 14$ & $17: 26: 44.0$ & 31.4 & 104 & 33 & 5.1 \\
$2008 / 5 / 13$ & $04: 45: 31.7$ & 31.7 & 104.5 & 33 & 5.2 \\
$2008 / 5 / 13$ & $04: 08: 50.1$ & 31.4 & 104 & 33 & 5.7 \\
$2008 / 5 / 12$ & $22: 46: 09.5$ & 32.7 & 105.5 & 33 & 5.1 \\
$2008 / 5 / 12$ & $16: 21: 47.3$ & 31.3 & 104.1 & 33 & 5.2 \\
\hline
\end{tabular}

and rake angles with $5^{\circ}$-intervals respectively. The $P_{\mathrm{nl}}$ is filtered between 0.03 and $0.3 \mathrm{~Hz}$ and the surface wave is filtered between 0.02 and $0.1 \mathrm{~Hz}$ to avoid waveform distortion due to 3D heterogeneity at higher frequencies (Zhu and Helmberger, 1996).

When the appropriate depth is assumed, the waveform fit error is minimized (Fig. A.2). At the optimal depth, the source mechanism is taken as the optimal mechanism. An example of waveform fit is displayed in Fig. 2, where red traces are synthetic seismograms and black traces are observed ones. Depth and mechanisms of the 18 events are listed in Table 3, and the focal mechanisms are displayed in Fig. 3. Most of the events occur deeper than $10 \mathrm{~km}$, and they can be as deep as $18 \mathrm{~km}$, except for events 7,14 , and 15 , whose depth is about $6 \mathrm{~km}$, and event 17 , whose depth is only $2 \mathrm{~km}$. The north-easternmost end has both the deepest event $(18 \mathrm{~km})$ and the shallowest event $(2 \mathrm{~km})$, indicating that the end is indeed the place of rupture arrest where a very complex stress field is expected. These aftershocks near the end also show an obvious temporal pattern with increasingly shallower depth (from event 9 , to events 14 and 15 , to event 17 over 3 months).

Ten of the 18 events show thrust mechanisms and are distributed along the length of the middle segment and north- 
Table 3. Depth and Focal mechanisms of the aftershocks $\left(>M_{\mathrm{s}} 5.0\right)$ from CAP and their relocated positions.

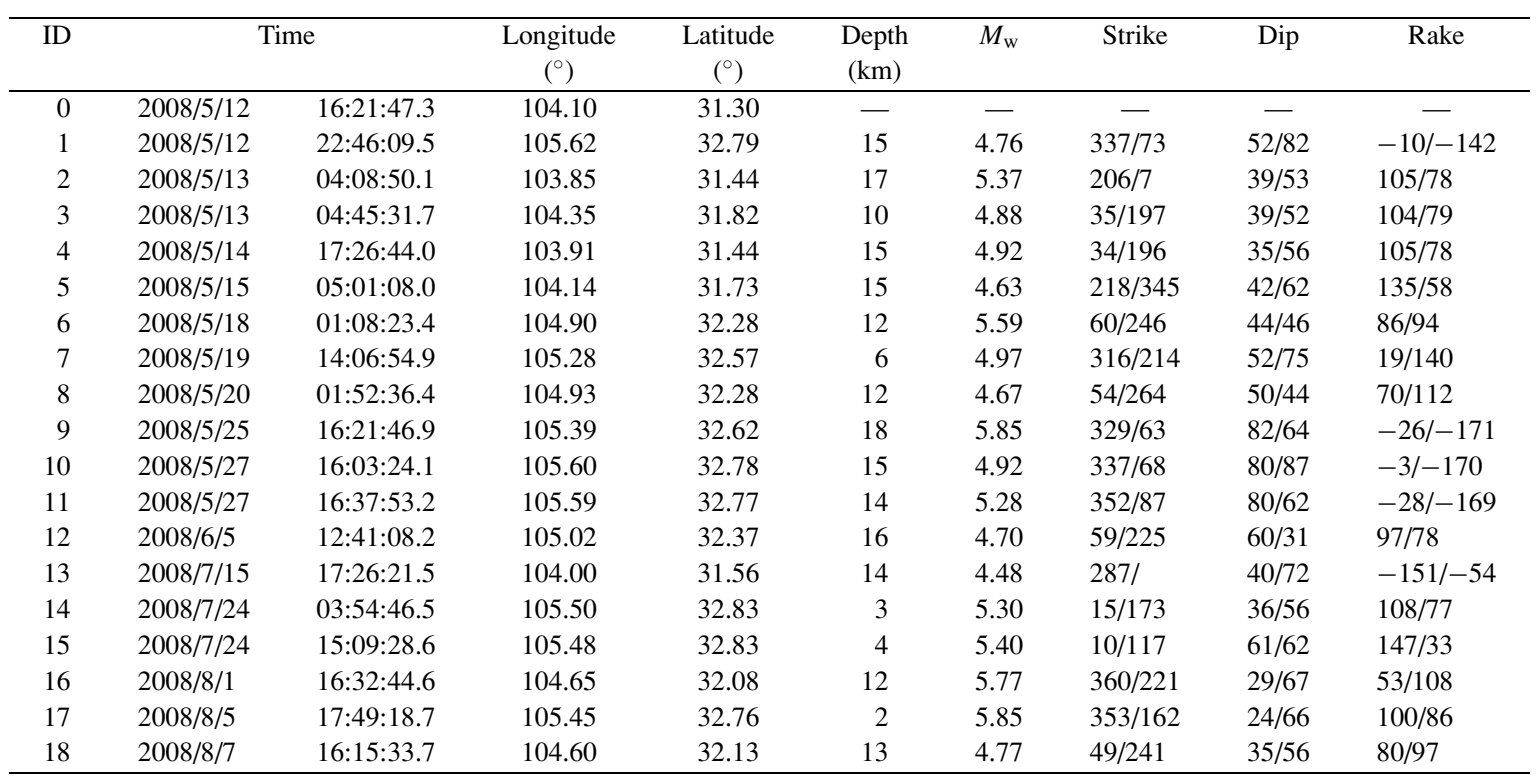

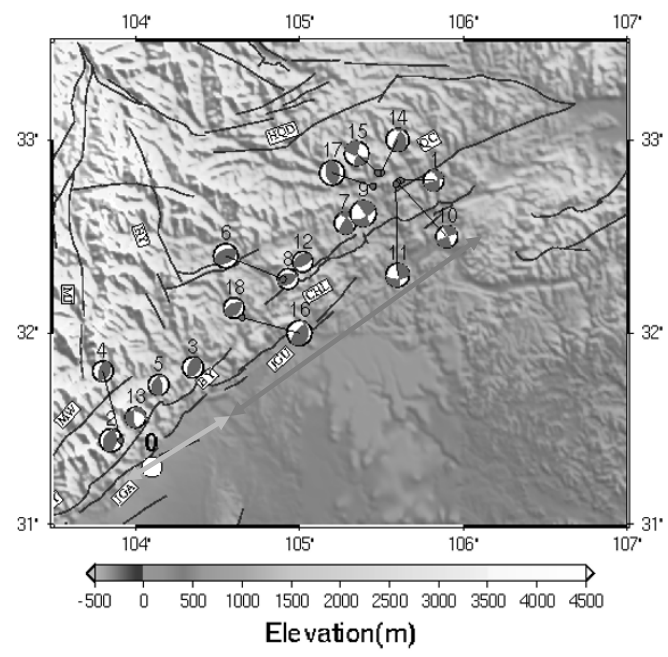

Fig. 3. Focal mechanisms of Wenchuan earthquake aftershocks with $M_{\mathrm{s}} \geq 5.0$ in the middle (green segment) and northern section (red segment). The number $1 \sim 18$ are the indexes of the aftershocks as defined in Table 3. Some events are plotted away from their epicenter (gray dots) when they might overlap with others. The gray lines are Quaternary faults. The abbreviated names of the faults are the same as those in Fig. 1. Earthquakes in the northernmost section show predominantly strike-slip mechanisms with a depth up to $18 \mathrm{~km}$, except for event 17 , which is a shallow thrust event (depth $2 \mathrm{~km}$ ).

ern segment. There are six events showing a predominant strike slip mechanism, but all of these occur at the northeasternmost end, not the northern segment. Puzzlingly, event 13 shows a normal mechanism, quite contrary to the transpressional tectonic stress demonstrated by many studies (Burchfiel et al., 1995, 2008).

\section{Discussion and Conclusion}

The north-easternmost end is one of the most interesting sections of the rupture zone. The narrow aftershock area (Fig. 1) suggests a high angle fault plane, and the deepest aftershock suggests deep rupture extent, consistent with

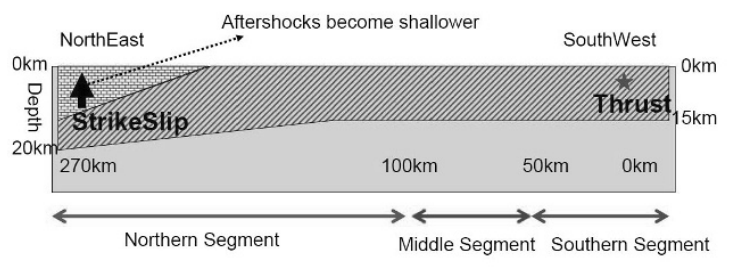

Fig. 4. Schematic relation between aftershocks and co-seismic rupture. The mainshock started with a thrust mechanism and transitioned into a strike-slip mechanism before rupture arrest with total rupture length of about $300 \mathrm{~km}$. Surface rupture is not observed for the north-easternmost $50 \mathrm{~km}$, and the early aftershocks occurred at depths up to $18 \mathrm{~km}$ while later aftershocks (late July and early August) became shallower, as little as $2 \mathrm{~km}$. These shallow earthquakes may be the result of filling the unruptured portion of the co-seismically ruptured fault. However, most other aftershocks in the northern segment and middle segment show thrust mechanisms, contrasting with the gradually increasing strike-slip component of surface rupture observed in the field.

teleseismic body wave inversion (Hayes and $\mathrm{Ji}, 2008$ ). The deep rupture is also consistent with the lack of surface rupture for the north-eastern most section. Also, the aftershocks become shallower from $18 \mathrm{~km}$ to $2 \mathrm{~km}$ within about 3 months, suggesting that the shallower part did not rupture, therefore leaving energy for producing aftershocks (Fig. 4). Indeed, 12 of 13 strong aftershocks $(M \geq 5.0)$ took place on the northern segment from May 18th to August 7th, 2008, which indicates a high potential for strong aftershock hazards in the northern segment. Some moderate to strong shallow aftershocks (>M 5.0) will probably occur in this region in the next few months. Since shallow earthquakes may be more damaging than deep ones, we suggest more work should be done on monitoring.

Aftershocks with strike slip mechanisms occurred only at the north-easternmost end, instead of being distributed over the northern segment. Also, most of the events other than those at the north-easternmost end demonstrated oblique thrust focal mechanisms, in contrast to the field observation 
of a focal mechanism with both thrust and strike-slip components (Liu et al., 2008), which is also in contrast with oblique strike-slip mechanism from teleseismic inversions in the northern segment (Hayes and Ji, 2008; Nishimura and Yagi, 2008).

The discrepancy between aftershock results and field observations can be explained by their different depths. The field observations are only for the surface breaks while the aftershocks occurred at depth. Also, the predominant strikeslip mechanism from teleseismic inversion could be an artifact of assuming a constant low dip angle, and the true dip angle in the northern segment could be high as manifested by the dip angles of focal mechanisms (event Nos. 1, 7, 9, 10, 11). Better finite fault modeling involving InSAR, GPS, and strong motion records should be able to clarify the discrepancy.

In summary, the presence of relocated aftershocks suggests changes in dip and strike angles for the three segments of the rupture zone, and the focal mechanism in the northern segment shows a mixture of thrust and strike mechanisms. In the future, when the depth of the smaller aftershocks can be better constrained from depth phases (Langston, 1987), a cross section of the aftershock pattern should provide clues to variable dip angle versus depth for the rupturing fault plane. Therefore, much more work has to be done on aftershocks to better understand the rupture process and seismotectonic setting of the Wenchuan Earthquake.

Acknowledgments. This study is supported by NSFC 40064004, NSFC 40674027, CAS grant kzcx2-yw-116-1, joint Earthquake Science Foundation A07124 and CMOST grant 2006BAC03B00. Contribution number 2008-005, Mengcheng National Geophysical Observatory.

\section{References}

Burchfiel, B. C., Z. Chen, Y. Liu, and L. H. Royden, Tectonics of the Longmenshan and adjacent regions, central China, Int. Geol. Rev., 37(8), 661-735, 1995 .

Burchfiel, B. C., L. H. Royden, R. D. van der Hilst, B. H. Hager, Z. Chen, R. W. King, C. Li, J. Lü, H. Yao, and E. Kirby, A geological and geophysical context for the Wenchuan earthquake of 12 May 2008, Sichuan, People's Republic of China, GSA today, 18, doi: 10.1130/GSATG18A.1, 2008.

Chi, W.-C. and E. Hauksson, Fault-perpendicular aftershock clusters following the $2003 \mathrm{Mw}=5.0$ Big Bear, California, earthquake, Geophys. Res. Lett., 33, L07301, doi: 10,1029/2005GL025033, 2006.

Geiger, L., Herdbestimmung bei Erdbeben aus den Ankunftszeiten, Nachrichten der K. Gesellschaft der Wissenschaften zu Göttingen, Math.-Phys. Klasse, 331-349, 1910.

Hayes, G. and C. Ji, http://neic.usgs.gov, 2008.

Langston, C., Depth of faulting during the 1968 Meckering, Australia, earthquake sequence determined from waveform analysis of local seismograms, J. Geophys. Res., 92, 11,561-11,574, 1987.

Liu, J., Z. Zhang, L. Wen, J. Sun, P. Tapponnier, X. Xing, G. Hu, Q, Xu, L. Zeng, and L. Ding, The 12 May 2008 Ms8.0 Wenchuan Earthquake, Sichuan, China: background, field investigations and tectonic implications, SCEC Workshop Proceedings, Palmsping, CA, USA, 2008.

Nishimura, N. and Y. Yagi, website, http://www.geol.tsukuba.ac.jp/ nisimura/20080512/ver1/index.html, 2008.

Song, H. B., The comprehensive interpretation of geological and geophysical data in the orogenic belt of Longmen mountains, China, J. Chendu Inst. Tech., 21(2), 79-88, 1996 (in Chinese).

Waldhauser, F. and W. L. Ellsworth, A double-difference earthquake location algorithm: Method and application to the northern Hayward fault, Bull. Seismol. Soc. Am., 90, 1353-1368, 2000.

Wang, W., L. Zhao, J. Li, and Z. Yao, Rupture processes of the Ms8.0 Wenchuan Earhtuqkae of Sichuan, China, Chinese J. Geophys., 51(5), 1403-1410, 2008 (in Chinese).
Wu, C. and M. Takeo, An intermediate deep earthquake rupturing on a dipbending fault: Waveform analysis of the 2003 Miyagi-ken Oki earthquake, Geophys. Res. Lett., 31, L24619, doi:10.1029/2004GL021228, 2004.

Zhang, P., X. Xu, X. Wen, and K. Ran, Slip rages and recurrence intervals of the Longmenshan active fault zone and the tectonic implications for the mechanism of the May 12 Wenchuan earthquake, 2008, Sichuan, China, Chinese J. Geophys., 51(4), 1066-1073, 2008 (in Chinese).

Zhao, L. S. and D. V. Helmberger, Source estimation from broadband regional seismograms, Bull. Seismol. Soc. Am., 84, 91-104, 1994.

Zhao, Z., J. Fan, and S. Zheng, Crustal structure and accurate hypocenter determination along the Longmenshan fault zone, Acta Seismol. Sinica, 10(6), 761-768, 1997.

Zheng, X. F., B. Ouyang, D. N. Zhang et al., Technical system construction of Data Backup Centre for China Seismograph Network and the data support to researches on the Wenchuan earthquake, Chinese J. Geophys., 52(5), 1412-1417, 2009 (in Chinese).

Zhu, L. and D. V. Helmberger, Advancement in source estimation techniques using broadband regional seismograms, Bull. Seismol. Soc. Am., 86, 1634-1641, 1996 .

Y. Zheng, S. Ni (e-mail: sdni@ustc.edu.cn), Z. Xie, J. Lv, H. Ma, and P. Sommerville

\section{Appendix A.}

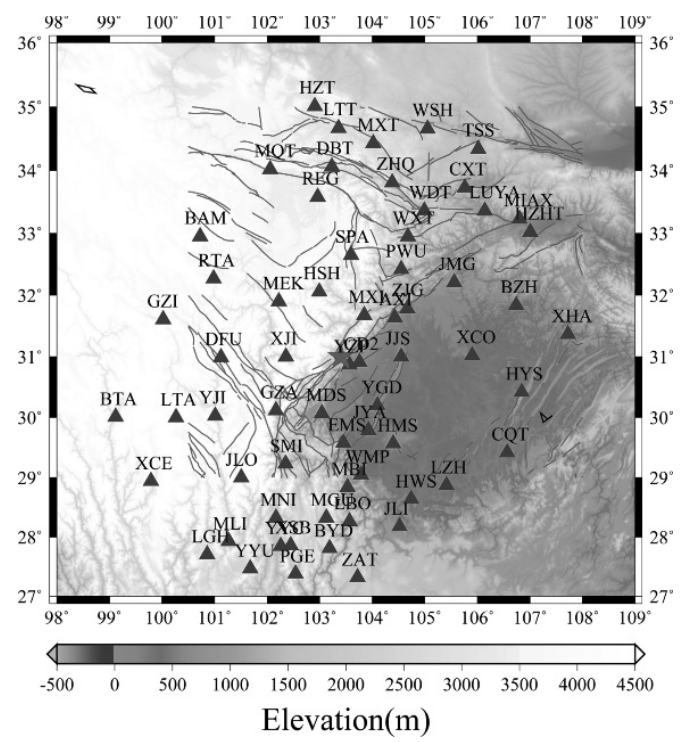

Fig. A.1. Distribution of broadband stations (triangle) from China National Seismograph Network and Sichuan, Gansu, Shaanxi Provincial networks. The star indicates the epicenter of the mainshock. The gray lines represent Quaternary active faults.

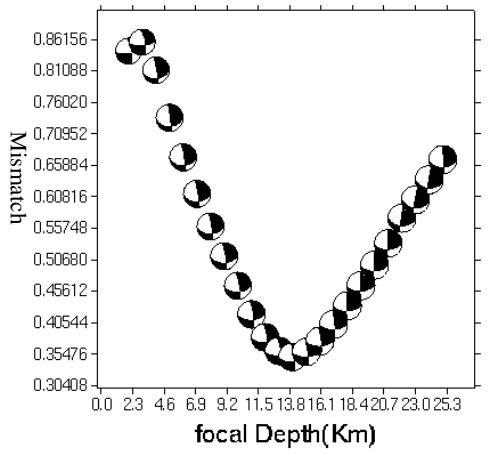

Fig. A.2. Depth sensitivity of CAP inversion for event 11 . When correct depth is used in grid-searching for mechanism, the waveform mismatch reaches minimum. The depth of event 11 turns to be at $14 \mathrm{~km}$. 